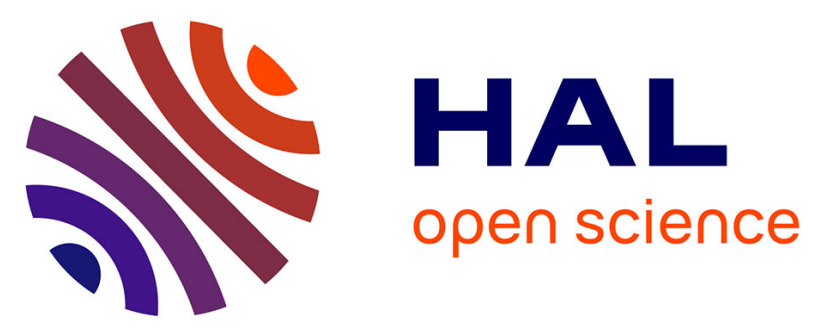

\title{
Molecular Assemblies from Imidazolyl-Containing Haloalkenes and Haloalkynes: Competition between Halogen and Hydrogen Bonding
}

Karim Bouchmella, Bruno Boury, Sylvain G. Dutremez, A. van Der Lee

\section{To cite this version:}

Karim Bouchmella, Bruno Boury, Sylvain G. Dutremez, A. van Der Lee. Molecular Assemblies from Imidazolyl-Containing Haloalkenes and Haloalkynes: Competition between Halogen and Hydrogen Bonding. Chemistry - A European Journal, 2007, 13 (21), pp.6130. 10.1002/chem.200601508 . hal00189513

\section{HAL Id: hal-00189513 \\ https://hal.science/hal-00189513}

Submitted on 21 Nov 2007

HAL is a multi-disciplinary open access archive for the deposit and dissemination of scientific research documents, whether they are published or not. The documents may come from teaching and research institutions in France or abroad, or from public or private research centers.
L'archive ouverte pluridisciplinaire HAL, est destinée au dépôt et à la diffusion de documents scientifiques de niveau recherche, publiés ou non, émanant des établissements d'enseignement et de recherche français ou étrangers, des laboratoires publics ou privés. 


\title{
Molecular Assemblies from Imidazolyl-Containing Haloalkenes and Haloalkynes: Competition between Halogen and Hydrogen Bonding
}

\author{
Karim Bouchmella, ${ }^{[a]}$ Bruno Boury, ${ }^{[a]}$ Sylvain G. Dutremez, ${ }^{*[a]}$ and Arie \\ van der Lee ${ }^{[b]}$
}

[a] K. Bouchmella, Prof. Dr. B. Boury, Dr. S. G. Dutremez

Laboratoire "Chimie Moléculaire et Organisation du Solide", UMR 5637

Université Montpellier II

Case Courrier 007

Place E. Bataillon

34095 Montpellier Cedex 5 (France)

Fax: (+33) 4-67-14-38-52

E-mail: dutremez@univ-montp2.fr

[b] Dr. A. van der Lee

Institut Européen des Membranes

CNRS - UMR 5635

Université de Montpellier II - Case Courrier 047

Place E. Bataillon

34095 Montpellier Cedex 5 (France) 
Abstract: The structural characterization of molecular assemblies constructed from imidazolyl-containing haloalkenes and haloalkynes is reported. 1-(3-Iodopropargyl)imidazole (2) and 1-(2,3,3-triiodoallyl)imidazole (5) have been synthesized from 1-propargylimidazole (1). In the solid state, these wholly organic modules self-assemble via $\mathrm{N}$...I halogen bonding interactions, giving rise to polymeric chains. The $\mathrm{N} \cdots \mathrm{I}$ interaction observed in $2(\mathrm{~d}(\mathrm{~N} \cdots \mathrm{I})=$ $\left.2.717 \AA, \angle \mathrm{C}(\mathrm{sp})-\mathrm{I} \cdots \mathrm{N}=175.8^{\circ}\right)$ is quite strong by comparison with literature data. The $\mathrm{N} \cdots \mathrm{I}$ interaction found in $5\left(\mathrm{~d}(\mathrm{~N} \cdots \mathrm{I})=2.901 \AA, \angle \mathrm{C}\left(\mathrm{sp}^{2}\right)-\mathrm{I} \cdots \mathrm{N}=173.6^{\circ}\right)$ is weaker, in accord with the ranking $\mathrm{C}(\mathrm{sp})-\mathrm{X} \leftarrow$ Base $>\mathrm{C}\left(\mathrm{sp}^{2}\right)-\mathrm{X} \leftarrow$ Base.

Compound 5 was found to give a 1:1 co-crystal (4) with morpholinium iodide (6). In the X-ray crystal structure of $4, \mathrm{~N} \cdots \mathrm{I}$ halogen bonding interactions similar to those observed in 5 are not present, the arrangement of the molecules being governed by two interwoven hydrogen bond networks. The first network involves $\mathrm{N}-\mathrm{H} \cdots \mathrm{O}$ interactions between nearby morpholinium cations, and the second network is based on $\mathrm{N}-\mathrm{H} \cdots \mathrm{N}$ hydrogen bonding between morpholinium cations and imidazolyl groups. Both hydrogen bonding schemes are charge-assisted. Halogen bonding is not completely wiped out, however, as the triiodoalkene fragment forms a halogen bond with an iodide anion in its vicinity $(\mathrm{d}(\mathrm{I} \cdots \mathrm{I})=3.470 \AA$, $\left.\angle \mathrm{C}\left(\mathrm{sp}^{2}\right)-\mathrm{I} \cdots \mathrm{I}=170.7^{\circ}\right)$.

The X-ray crystal structure of morpholinium iodide (6) is also reported. It shows a completely different arrangement from that observed in 4, i.e., $\mathrm{N}-\mathrm{H} \cdots \mathrm{O}$ interactions are not present. In crystalline 6, morpholinium cations are interconnected via $\mathrm{C}-\mathrm{H} \cdots \mathrm{O}$ bridges $(\mathrm{d}(\mathrm{H} \cdots \mathrm{O})=2.521$ and $2.676 \AA)$, and the $\mathrm{NH}_{2}{ }^{+}$groups interact with nearby iodide anions $(\mathrm{d}(\mathrm{H} \cdots \mathrm{I})=2.633$ et $2.698 \AA)$. 


\section{Introduction and Background}

Currently, an intense research effort is being devoted to the construction of wholly organic architectures with controlled topologies by use of non covalent bonding. This modular approach circumvents the making of a large number of covalent bonds, which simplifies the synthetic task and minimizes the chances of side-reactions. This activity encompasses several areas of research such as supramolecular chemistry, crystal engineering, and materials science. One motivation for the synthesis of wholly organic architectures is their topological resemblance to existing inorganic systems and, as a result, it is often found that the former exhibit behaviours similar to those of the latter. For instance, wholly organic structures are capable of assembling into $2 \mathrm{D}^{[1,2]}$ and $3 \mathrm{D}^{[3]}$ networks that resemble structurally and functionally pillared clays and zeolites.

These structures are held together via an appropriate synthon which, very often, relies on hydrogen-bonding or charge-assisted hydrogen bonding. Among the most frequently used moieties with hydrogen bonding capabilities pyridine and its analogues occupy the first rank, as well as carboxylates. Another building block that has become quite popular in recent years is imidazole, and the chemistry of this heterocycle is now getting quite rich and versatile. Indeed, many facets of imidazole chemistry resemble aspects of pyridine chemistry. Just like pyridine, imidazole is capable of assembling via acid-base chemistry with a large number of molecules possessing acidic sites, especially carboxylic acids, and form numerous coordination complexes with many metals. ${ }^{[4,5]}$ Alkylation of imidazoles gives imidazolium salts that show many similarities with pyridinium salts, and these salts have proven interesting for a number of reasons: some of them are liquid at or just above room temperature, or exhibit liquid crystallinity. ${ }^{[6,7]}$ Imidazolium-based ionic liquids are used as media in organic reactions because they are environmentally benign and, in some cases, they perform better than usually used organic solvents. ${ }^{[8]}$ Due to their high ionic conductivities, ${ }^{[9]}$ they have considerable potentials as electrolytes for batteries and capacitors. Finally, imidazolium salts are useful starting materials for the preparation of metal complexes bearing N-heterocyclic carbene ligands. ${ }^{[10]}$

In recent years, halogen bonding has become an increasingly important interaction in crystal engineering for the assembly of small organic building blocks. ${ }^{[11]}$ It is a charge transfer interaction of the $\mathrm{n} \rightarrow \sigma^{*}$ type between an electron-rich atom and an halogen, bonded to an electron-deficient organic fragment or belonging to a dihalogen molecule. ${ }^{[12]}$ It is a directional interaction that shows many similarities with hydrogen bonding: its strength depends not 
only on the distance between bonded atoms but, also, on the $\mathrm{D} \cdots \mathrm{X}-\mathrm{Y}$ angle ( $\mathrm{D}=$ donor atom; $\mathrm{X}=$ halogen; $\mathrm{Y}=$ carbon, halogen). Furthermore, it was suggested early on that halogen bonding might be comparable in energy with hydrogen bonding, ${ }^{[13]}$ and recent results from computational studies ${ }^{[14]}$ have confirmed this.

A large body of literature is available concerning halogen bonding where the donor is a nitrogen-containing group, especially pyridine and its analogues. ${ }^{[12,15-24]}$ Surprisingly, reports are quite scarce concerning the study of halogen-bonded systems in which imidazolyl groups take part. The diiodine basicity of imidazoles has been measured by means of the formation constant of diiodine-imidazole complexes in heptane at $298 \mathrm{~K}$, ${ }^{[25]}$ but no report has been published concerning the structural characterization of architectures sustained by halogen bonding where imidazolyl groups are involved. C-Halogen $\cdots \mathrm{N}$ interactions have been observed in the X-ray crystal structures of Schiff-base-containing triazoles and 5bromotetrazole, ${ }^{[26,27]}$ but such interactions are overpowered by hydrogen bonding in the solid state structures of 3-chloro-1H-1,2,4-triazole and 3-bromo-1H-1,2,4-triazole. ${ }^{[28]}$

The electron-poor part of the charge transfer complex is generally an electrondeficient organic halide, and so 1,4-diiodotetrafluorobenzene has been used quite extensively. ${ }^{[12,15,16,18,24,29,30]}$ Halogen bonding in which the halide is attached to a double bond or a triple bond is known, but these systems have been the subject of much fewer studies. Polymeric chains result from the interaction between tetraiodoethylene and diamines. ${ }^{[16,31]}$ Also, this alkene has been co-crystallized with various diacetylenic molecules with the hope of getting host-guest complexes in which the diacetylenic fragments are suitably oriented for topochemical polymerisation. ${ }^{[32,33]}$ Halogen bonding involving haloalkynes has been studied both in the solid state and in solution. Various complexes between 1-halo-2-phenylacetylenes and halide ions have been prepared, and the structures and stoichiometries of these complexes were found to depend on the nature of the halide ion and type of organic cation. ${ }^{[34-36]}$ Polymers with 1:1 stoichiometries result from the interaction of diiodoacetylene with halide ions, ${ }^{[36-38]}$ and a polymeric network is also obtained by cocrystallization of diiodohexatriyne with triphenylphosphine oxide. ${ }^{[39]}$ In that connection, Goroff et al. recently reported some spectacular results: these authors succeeded in polymerising diiododiacetylene in the solid state despite the explosiveness of this molecule. This "tour de force" was achieved by forming halogen bonded complexes between diiododiacetylene and oxalamide-containing hosts terminated with nitrile groups at both ends. $^{[40]}$ In these host-guest complexes, the diacetylenic guest is suitably oriented for topochemical polymerisation. Previous attempts to do the same using host molecules that 
possessed pyridyl groups instead of nitrile groups had been unsuccessful due to steric problems. ${ }^{[41]}$

In solution, the strength of interaction of 1-iodoacetylenes with Lewis bases has been measured by means of vibrational spectroscopy, ${ }^{[42]}$ and this technique has proven very useful to determine the formation constants of such acid-base complexes. ${ }^{[43]}$ The interaction between DMSO- $d_{6}$ and diiodohexatriyne and diiodooctatetrayne has been investigated by means of ${ }^{13} \mathrm{C}$ NMR spectroscopy. It was found that the chemical shifts of the carbon atoms bonded to iodine moved from about $1 \mathrm{ppm}$ in $\mathrm{CDCl}_{3}$ to approximately $15 \mathrm{ppm}$ in DMSO- $d_{6}$, and this effect was attributed to polarization of the iodoalkyne triple bond in a Lewis acid-base complex with the solvent. ${ }^{[39]}$ These results were reproduced computationally. ${ }^{[44]}$ Additional support to this interpretation was obtained from the good correlations with various empirical models of solvent basicity, including Gutmann's donor numbers and Taft and Kamlet's $\beta$ values. ${ }^{[45]}$ Furthermore, poor correlations to Reichardt's $E^{\mathrm{N}} \mathrm{T}$ and Taft and Kamlet's $\pi^{*}$ parameters were found that suggest that solvent polarity does not play a role. ${ }^{[45]}$ Interestingly, the ${ }^{13} \mathrm{C}$ resonance of the I-Csp ${ }^{2}$ moiety of iodoarenes does not undergo a downfield shift on passing from a noncoordinating solvent to a coordinating one, even though complexation occurs. ${ }^{[46]}$ It was proposed that this is because the nonrelativistic complexation shifts and the change in the spin-orbit induced heavy atom effect of iodine compensate each other.

We describe herein the syntheses of wholly organic architectures in which halogen bonding interactions between imidazolyl groups and haloalkene and haloalkyne moieties are present. This structural study provides new examples of the utilization of imidazole in the construction of self-assembled networks and improves the current knowledge of halogen bonding with halogenated alkenes and alkynes. The molecules that have been selected are 1(3-iodopropargyl)imidazole (2) and 1-(2,3,3-triiodoallyl)imidazole (5). Insight into the solidstate organization of these organic modules is of paramount importance to design novel functional materials with specific properties (high microporosity, non-linear optical response, liquid crystallinity) and quite valuable in case solid-state reactivity is sought. Also, these compounds are good models for future computational studies. The approach followed here is similar to that chosen by Czugler, ${ }^{[17]}$ van der Boom, ${ }^{[23]}$ Drabent, ${ }^{[26]}$ and others, ${ }^{[47]}$ i.e., the acceptor and donor sites are present in the same molecule. By doing so, chances are minimum for disturbance by competing interactions. We also report that these $1 \mathrm{D}$ heteroditopic tectons are capable of forming co-crystals with other organic modules possessing hydrogen bonding capabilities and that, in this case, halogen bonding is no longer the structure-directing interaction in the solid. 


\section{Results and Discussion}

Syntheses: 1-Propargylimidazole (1) is a known compound that has been prepared in the past by $N$-propargylation of imidazole using different methods. ${ }^{[48]}$ Alternative procedures utilize microwave irradiation in the presence of various types of magnesium oxide catalysts, or make use of solid-liquid phase transfer catalysis conditions. ${ }^{[49,50]}$ In some cases the reaction is complicated by the formation of substantial amounts of 1-propadienyl-1H-imidazole. ${ }^{[50 \mathrm{a}]} \mathrm{We}$ have prepared $\mathbf{1}$ by the reaction between lithiated imidazole and propargyl bromide in anhydrous THF at $-78{ }^{\circ} \mathrm{C}$. The yield is $82 \%$ after purification by distillation under reduced pressure.

1-(3-Iodopropargyl)imidazole (2) and 1-(2,3,3-triiodoallyl)imidazole (5) have been synthesized before and tested for antibacterial and antifungal activities. ${ }^{[51]}$ Compound 2 was obtained by allowing imidazole to react with 3-iodopropargyl 4-methylbenzenesulfonate in DMF at room temperature. Compound 3 was prepared similarly by using 2,3,3-triiodoallyl 4methylbenzenesulfonate instead of 3-iodopropargyl 4-methylbenzenesulfonate. Our synthetic approach is different (Scheme 1): iodoalkyne $\mathbf{2}$ was synthesized by allowing alkyne $\mathbf{1}$ to react with $\mathrm{N}$-iodosuccinimide in the presence of $10 \%$ molar $\mathrm{AgNO}_{3}{ }^{[52]}$ Elemental analysis of the resulting pale yellow solid gave unsatisfactory results. Furthermore, energy dispersive spectroscopy (EDS) measurements showed that large amounts of silver were present in the solid, presumably coordinated to the imidazole ring of $\mathbf{2}$. Several attempts were made to remove the silver by decomplexation with dithizone, $\mathrm{KCN}$, and 1,4,8,11tetraazacyclotetradecane, but these attempts led to decomposition of the product or met with only limited success. The best method we have found to purify the material consists in washing the crude solid on a glass frit with hot acetonitrile, reducing the volume of the filtrate on a rotary evaporator, and allowing the material to crystallize in a freezer.

Iodination of 1 with three equivalents of iodine-morpholine complex does not lead to 2 but, instead, solid $\mathbf{3}$ is obtained. A ${ }^{1} \mathrm{H}$ NMR analysis showed that $\mathbf{3}$ is a mixture of $\mathbf{5}$ and morpholinium iodide in a 1:3 ratio (Scheme 1). It is noteworthy that $\mathbf{3}$ is obtained even when an excess of $\mathbf{1}$ is used. Clearly, under these conditions, addition of iodine across the triple bond of $\mathbf{2}$ is more facile than iodination of $\mathbf{1}$. Washing $\mathbf{3}$ with acetonitrile yields another solid (4) whose composition is $\mathbf{5} \cdot 1$ morpholinium iodide. As will be seen later, the fraction of morpholinium iodide that is not washed away is part of a co-crystal with $\mathbf{5}$. Compound $\mathbf{5}$ is obtained by suspending 4 in a saturated aqueous solution of $\mathrm{NaHCO}_{3}$.

Scheme 1, here 
Structure of 2: X-ray quality crystals of 2 were obtained by dissolving a small amount of powder in acetonitrile and allowing the solution to come slowly to dryness. In the solid (Table 1), molecules of 2 form layers that pile up along $a$ (Figure 1). Looking at one layer from the top, one can see polymeric chains that run along the $c$-axis. These chains look like undulating wires and are the result of $\mathrm{C}(\mathrm{sp})-\mathrm{I} \cdots \mathrm{N}$ interactions between molecules. These findings explain why $\mathbf{2}$ is only soluble in coordinating solvents like dimethylsulfoxide and acetonitrile: the $\mathrm{C}(\mathrm{sp})-\mathrm{I} \cdots \mathrm{N}$ interactions must be broken for the solid to dissolve. The $\mathrm{N} \cdots \mathrm{I}$ distance is 2.717 $\AA$ and the $\mathrm{C}(\mathrm{sp})-\mathrm{I} \cdots \mathrm{N}$ angle $175.8^{\circ}$. These values are indicative of strong halogen bonding interactions. ${ }^{[11]}$ The $\mathrm{I} \cdots \mathrm{N}$ distance is longer than that found in the $\mathrm{PhC} \equiv \mathrm{CI} \cdot$ morpholine complex $(2.51 \AA)^{[53]}$ and shorter than the $\mathrm{I} \cdots \mathrm{N}$ distance in solid IC $\equiv \mathrm{CCN}(2.93 \AA) .{ }^{[54]}$ This is consistent with the fact that morpholine is a stronger base than imidazole $\left(\mathrm{p} K_{\mathrm{b}}(\right.$ morpholine $)=$ $5.5 ; \mathrm{p} K_{\mathrm{b}}($ imidazole $\left.)=7.01\right)$, and the fact that nitrile groups are only weakly basic moieties. There are no I $\cdots \pi$ interactions as those observed in Adams' platinum-alkynyl compounds. ${ }^{[55]}$ This is because the nitrogen atom at the 3 -position of the imidazole ring is more basic than the $\pi$ cloud of the triple bond. It is also noteworthy that acetonitrile molecules are not present in the structure. There again, these findings agree with the fact that imidazolyl groups are stronger bases than nitrile moieties. Neighbouring imidazole groups in each layer are parallel. The centroid-centroid distance between adjacent rings is $4.377 \AA$, and the angle between the centroid-centroid vector and the ring normal $40.9^{\circ}$. These parameters are indicative of weak $\pi \cdots \pi$ interactions. ${ }^{[56-58]}$ Yet, given the large number of such interactions in 2 , it is likely that their contribution to stabilization of the structure is not nil. There is also a C-H $\cdots \pi$ contact between the methylene group of one molecule and the imidazole ring of an adjacent molecule in the same layer. The $\mathrm{H} \cdots \mathrm{Cg}$ distance is $2.70 \AA$, the $\mathrm{C}-\mathrm{H} \cdots \mathrm{Cg}$ angle $132.0^{\circ}$, and the angle between the $\mathrm{H}-\mathrm{Cg}$ axis and $\mathrm{H}-\mathrm{Hperp}$ vector $6.6^{\circ}$ ( $\mathrm{Cg}$ is the centroid position and Hperp is the orthogonal projection of the $\mathrm{H}$ position onto the ring). This weak interaction is of type III according to Malone's classification, ${ }^{[59]}$ and the $\mathrm{H} \cdots \mathrm{Cg}$ distance is the same as that typically found in complexes between alkanes and aromatics. ${ }^{[60]}$

Figure 1, here

Structure of 5: X-ray quality crystals of 5 were grown from acetonitrile. In the solid state (Table 1), molecules of 5 pile up in stacks in the $a$-direction (Figure 2). The stacks are not isolated but interact with one another: a cut through the stacks along the $b c$ plane shows that alkene 5 self-assembles into polymeric chains that run parallel to the $b$-axis. The molecules are interconnected via halogen bonds, each halogen bond involving the imidazolyl group of 
one molecule and the $=\mathrm{CI}_{2}$ fragment of the next molecule. The chains are zigzag shaped due to the crooked form of the organic module. In each molecule, the imidazolyl group and the $\mathrm{CI}=\mathrm{CI}_{2}$ fragment lie almost perpendicular to each other. Intermolecular $\mathrm{I} \cdots \mathrm{N}$ distances are $2.901 \AA$ and $\mathrm{C}\left(\mathrm{sp}^{2}\right)-\mathrm{I} \cdots \mathrm{N}$ angles $173.6^{\circ}$, which indicates that this interaction is reasonably strong. However, it is weaker than that observed in alkyne $\mathbf{2}$, in accordance with the ranking $\mathrm{C}(\mathrm{sp})-\mathrm{X} \leftarrow$ Base $>\mathrm{C}\left(\mathrm{sp}^{2}\right)-\mathrm{X} \leftarrow$ Base $>\mathrm{C}\left(\mathrm{sp}^{3}\right)-\mathrm{X} \leftarrow$ Base. ${ }^{[11]}$ The $\mathrm{I} \cdots \mathrm{N}$ distance reported here is slightly shorter than those observed previously in complexes of tetraiodoethylene (TIE) with nitrogen bases. ${ }^{[16,32,33]}$ The only exceptions are 1,2-bis(4-pyridyl)ethylene. TIE $(2.840 \AA)^{[16]}$ and 1,4-bis(3-quinolyl)-1,3-butadiyne-TIE (2.884 $\AA$ ). ${ }^{[33]}$ The centroid-centroid distance between two adjacent imidazole rings in one stack is $4.795 \AA$, and the angle between the centroid-centroid vector and the ring normal is $50.1^{\circ}$. These parameters are indicative of negligible $\pi \cdots \pi$ interactions. ${ }^{[56-58]}$ In addition, $\mathrm{CH}_{2} \cdots$ imidazole contacts similar to those observed in solid $\mathbf{2}$ are not present.

Figure 2, here

Structure of 4: Single crystals of $\mathbf{4}$ were grown from acetonitrile. A view of the packing is shown in Figure 3 and the corresponding crystallographic data are listed in Table 1. Close inspection of the structure shows that there is no stacking of the molecules as that noted in crystalline $\mathbf{2}$ and $\mathbf{5}$. Furthermore, the $\mathrm{I} \cdots \mathrm{N}$ halogen bonding interactions observed in $\mathbf{5}$ are no longer present. There is however one halogen bond between the iodide anion and one iodine atom from the $=\mathrm{CI}_{2}$ fragment. The $\mathrm{I} \cdots \mathrm{I}$ distance is $3.470 \AA$ and the $\mathrm{I} \cdots \mathrm{I}-\mathrm{C}\left(\mathrm{sp}^{2}\right)$ angle $170.7^{\circ}$. This interaction is appreciably stronger than that found in the $\left[2,2^{\prime}-b p y(H)\right] I_{3}$. TIE complex for which I $\cdots$ I contacts between the TIE molecules and the triiodide anions amount to 3.643 and $3.672 \AA .{ }^{[61]}$ The organization of $\mathbf{4}$ is governed by two hydrogen bond networks that are interwoven: the first network involves $\mathrm{N}-\mathrm{H} \cdots \mathrm{O}$ interactions between nearby morpholinium cations, and the second network is based on $\mathrm{N}-\mathrm{H} \cdots \mathrm{N}$ hydrogen bonding between morpholinium cations and imidazolyl groups. Both hydrogen bonding schemes are chargeassisted. Interactions between morpholinium cations generate polymeric chains. The $\mathrm{N}^{+} \mathrm{H} \cdots \mathrm{O}$ distance is $1.983 \AA$, the $\mathrm{N} \cdots \mathrm{O}$ contact $2.843 \AA$, and the $\mathrm{N}^{+} \mathrm{H} \cdots \mathrm{O}$ angle $180.0^{\circ}$. The $\mathrm{N}^{+} \mathrm{H} \cdots \mathrm{O}$ and $\mathrm{N} \cdots \mathrm{O}$ distances are comparable to those found in the X-ray crystal structures of morpholinium pentaiodide $\left(\mathrm{N}^{+} \mathrm{H} \cdots \mathrm{O}=2.102 \AA, \mathrm{N} \cdots \mathrm{O}=2.863 \AA\right)^{[62]}$ and morpholinium triiodide $\left(\mathrm{N}^{+} \mathrm{H} \cdots \mathrm{O}=2.13\right.$ and $2.18 \AA, \mathrm{N} \cdots \mathrm{O}=2.849$ and $\left.2.838 \AA\right) .{ }^{[63]}$ However, the $\mathrm{N}^{+} \mathrm{H} \cdots \mathrm{O}$ angle observed in crystalline $\mathbf{4}$ is flat, which suggests that the hydrogen bonding interaction is stronger $\left(\angle \mathrm{N}^{+} \mathrm{H} \cdots \mathrm{O}=125.1^{\circ}\right.$ in morpholinium pentaiodide and 157 and $148^{\circ}$ in 
morpholinium triiodide). The $\mathrm{N}^{+} \mathrm{H} \cdots \mathrm{N}$ distance is $1.790 \AA$, the $\mathrm{N} \cdots \mathrm{N}$ distance $2.797 \AA$, and the $\mathrm{N}^{+} \mathrm{H} \cdots \mathrm{N}$ angle $179.8^{\circ}$. The only reported structure in which an imidazolyl nitrogen interacts with a $\mathrm{NH}_{2}^{+}$fragment is that of 1-hydroxymethyl-4,5,6,7-tetrahydro- $1 \mathrm{H}$ imidazo(4,5-c)pyridine-6-carboxylic acid monohydrate. ${ }^{[64]}$ In this case, the $\mathrm{N}^{+} \mathrm{H} \cdots \mathrm{N}$ distance is $1.956 \AA$, the $\mathrm{N} \cdots \mathrm{N}$ contact $2.824 \AA$, and the $\mathrm{N}^{+} \mathrm{H} \cdots \mathrm{N}$ angle $171.5^{\circ}$.

Figure 3, here

The binding of $\mathrm{H}^{+}$to the morpholine nitrogen rather than to the imidazolyl nitrogen agrees with the fact that morpholine is a stronger base than imidazole (see aforementioned $\mathrm{p} K_{\mathrm{b}}$ values). However, there exist examples in the literature where the protonation scheme disagrees with acidity constants derived from solution. This phenomenon was observed in the X-ray crystal structure of $\left[\mathrm{NH}_{2}\left(\mathrm{CH}_{3}\right)_{2}\right]_{12}\left[\mathrm{H}_{3} \mathrm{TMA}\right]\left[\mathrm{H}_{2} \mathrm{TMA}\right]_{3}[\mathrm{HTMA}]_{3}[\mathrm{TMA}]\left(\mathrm{H}_{3} \mathrm{TMA}=\right.$ trimesic acid). ${ }^{[65]} \mathrm{We}$ have obtained confirmation that our assignement is correct by comparing the $\mathrm{C}-\mathrm{N}$ bond lengths of the imidazole ring and the $\mathrm{C}-\mathrm{N}$ distances of the morpholinium cation with known data. For the imidazole ring, the $\mathrm{C}(12)-\mathrm{N}(8)$ bond length is $1.369 \AA$ and the $\mathrm{C}(12)-\mathrm{N}(11)$ distance $1.301 \AA$ (Figure 4). These values lie in the same range as those found in 5: $\mathrm{d}(\mathrm{C}-\mathrm{N})=1.344 \AA$ and $\mathrm{d}(\mathrm{C}=\mathrm{N})=1.318 \AA$. A search through the Cambridge Structural Database (CSD) indicates that for neutral imidazole moieties the mean $\mathrm{C}-\mathrm{N}$ distance is $1.356 \AA$ and the mean $\mathrm{C}=\mathrm{N}$ bond length $1.313 \AA{ }^{[66]}$ These distances tend to become almost equal when the imidazole nitrogen is protonated or alkylated $($ mean $\mathrm{d}(\mathrm{C}-\mathrm{N})=$ $1.326 \AA$ and mean $\mathrm{d}(\mathrm{C}=\mathrm{N})=1.323 \AA) .{ }^{[66]}$ Concerning the morpholinium cation, the $\mathrm{C}(15)$ $\mathrm{N}(16)$ bond length is $1.478 \AA$ and the $\mathrm{C}(17)-\mathrm{N}(16)$ distance $1.490 \AA$ (Figure 4). These values are similar to those observed in the X-ray crystal structure of morpholinium iodide (6) discussed below, i.e., $\mathrm{d}(\mathrm{C}-\mathrm{N})=1.494$ and $1.488 \AA$. In addition, they are much longer than the $\mathrm{C}-\mathrm{N}$ distances found in the $150 \mathrm{~K}$ structure of morpholine, i.e. 1.466 and $1.469 \AA^{[67]}$

Figure 4, here

Structure of 6: Single crystals of morpholinium iodide (6) were obtained by slow concentration of the filtrate resulting from the washing of $\mathbf{3}$ with acetonitrile. A view of the packing is shown in Figure 5 and the corresponding crystallographic data are listed in Table 1. The structure of $\mathbf{6}$ differs significantly from that of $\mathbf{4}$ in that it is not sustained by $\mathrm{N}-\mathrm{H} \cdots \mathrm{O}$ interactions. In crystalline 6, morpholinium cations are interconnected via $\mathrm{C}-\mathrm{H} \cdots \mathrm{O}$ bridges $(\mathrm{d}(\mathrm{H} \cdots \mathrm{O})=2.521$ and $2.676 \AA)$, and the $\mathrm{NH}_{2}{ }^{+}$groups interact with nearby iodide anions $(\mathrm{d}(\mathrm{H} \cdots \mathrm{I})=2.633$ et $2.698 \AA)$. The $\mathrm{C}-\mathrm{H} \cdots \mathrm{O}$ contacts observed here are close to the mean $\mathrm{H} \cdots \mathrm{O}$ distance found for complexes in which a $\mathrm{CH}_{2} \mathrm{Cl}_{2}$ molecule interacts with a C-O-C acceptor $(2.50 \AA) .{ }^{[68]}$ Furthermore, similar $\mathrm{C}-\mathrm{H} \cdots \mathrm{O}$ bridges were found to govern the 
organization of morpholine in the solid state $(\mathrm{H} \cdots \mathrm{O}$ distance $=2.63 \AA) .{ }^{[67]}$ Concerning N$\mathrm{H} \cdots \mathrm{I}$ contacts, those observed in $\mathbf{6}$ are much shorter than that found in the X-ray crystal structure of morpholinium pentaiodide $(2.788 \AA) .{ }^{[62]}$ Also, N-H $\cdots$ I angles are wider (161.6 and $152.6^{\circ}$ in 6 versus $148.8^{\circ}$ in morpholinium pentaiodide).

Figure 5, here 


\section{Conclusion}

The work described herein provides new examples of the utilization of imidazole in crystal engineering and improves the current knowledge of halogen bonding with halogenated alkenes and alkynes. 1-(3-Iodopropargyl)imidazole (2) and 1-(2,3,3-triiodoallyl)imidazole (5) have been synthesized and their solid-state organization studied. As anticipated, these wholly organic modules self-assemble via $\mathrm{N} \cdots \mathrm{I}$ halogen bonding interactions. The $\mathrm{N} \cdots \mathrm{I}$ interaction observed in $\mathbf{2}$ is quite strong by comparison with data surveyed by Metrangolo and Resnati. ${ }^{[11]}$ The N...I interaction found in $\mathbf{5}$ is weaker, in accord with the ranking $\mathrm{C}(\mathrm{sp})-\mathrm{X} \leftarrow \mathrm{Base}>$ $\mathrm{C}\left(\mathrm{sp}^{2}\right)-\mathrm{X} \leftarrow$ Base. ${ }^{[11]}$ The use of linear modules has made possible the preparation of polymeric chains that run throughout the solid. The use of organic modules with shapes other than linear should make possible the preparation of 3D networks with open cavities. In addition, this work provides valuable information that can be used to organize suitably diacetylenic molecules for solid-state polymerisation, as demonstrated recently by Goroff and colleagues. $^{[40]}$

We also report that these molecules are capable of forming co-crystals with other organic modules possessing hydrogen bonding capabilities, as testified by the X-ray crystal structure of 4. In this case, the N...I halogen bonding scheme observed in $\mathbf{5}$ is disrupted because the imidazolyl group, the most basic moiety in the molecule, is part of the hydrogen bond network. Nonetheless, halogen bonding is quite persistent since the triiodoalkene fragment is found to participate in a halogen bond with a surrounding anion.

Attempts are currently being made in our laboratory to modify the solid-state organisation of $\mathbf{2}$ and $\mathbf{5}$ in order to prepare novel functional materials. In particular, complexation of the imizadole nitrogen with a metal is being investigated. Other types of halogen bonding schemes are also being tested, especially via alkylation of the imidazole nitrogen with an alkyl halide ${ }^{[69]}$ or using pyridinium perhalometallate salts similar to those utilized by Brammer and co-workers. ${ }^{[70]}$ 


\section{Experimental Section}

General considerations: The synthesis of 1 was carried out under an inert atmosphere of argon using standard Schlenk-line techniques. Tetrahydrofuran (THF) was distilled over sodium-benzophenone ketyl prior to use.

Solution ${ }^{1} \mathrm{H}$ and ${ }^{13} \mathrm{C}$ NMR spectra were obtained on a Bruker Avance DPX 200 instrument. ${ }^{1} \mathrm{H}$ chemical shifts were referenced to the protio impurity of the NMR solvent and ${ }^{13} \mathrm{C}$ chemical shifts to the NMR solvent. Infrared spectra were recorded on a Thermo Nicolet Avatar 320 FT-IR spectrometer with a $4 \mathrm{~cm}^{-1}$ resolution. FAB mass spectra were obtained on a Jeol JMS-SX102A instrument and ESI mass spectra on a Micromass QTOF spectrometer. Melting points were measured on a Büchi B-540 melting point apparatus and are uncorrected. EDS measurements were carried out using an Oxford X-ray detector mounted on a Cambridge S360 Scanning Electron Microscope. Prior to EDS analysis, the sample was coated with thermally evaporated carbon. $\mathrm{C}, \mathrm{H}, \mathrm{N}, \mathrm{O}$ elemental analyses were performed inhouse using a Thermo Finnigan FLASH EA 1112 Series analyser. Determination of the iodine contents was carried out at the Service Central de Microanalyse of the Centre National de la Recherche Scientifique (CNRS), Vernaison, France.

Materials: The following chemicals were obtained from commercial sources and used as supplied: imidazole (Aldrich), $2.5 \mathrm{M}$ solution of $n$-butyllithium in hexanes (Aldrich), 80 weight $\%$ solution of propargyl bromide in toluene (Aldrich), $\mathrm{N}$-iodosuccinimide (Acrōs Organics), silver nitrate (Fluka), morpholine (Lancaster), sodium hydrogencarbonate (Prolabo).

Synthesis of 1-propargylimidazole (1): A $8.51 \mathrm{~g}$ portion of imidazole $(0.125 \mathrm{~mol})$ was introduced in a 250-mL two-necked flask containing a magnetic stir-bar, equipped with a pressure-equalizer dropping funnel. The solid was dissolved in $100 \mathrm{~mL}$ of anhydrous THF and the solution cooled to $-78^{\circ} \mathrm{C}$. A $50 \mathrm{~mL}$ portion of $n \mathrm{BuLi}$ solution $(0.125 \mathrm{~mol})$ was added dropwise. The mixture was kept at $-78{ }^{\circ} \mathrm{C}$ for two hours, during which time a white precipitate formed. The suspension was transferred, via a canula, into a second flask containing a cold $\left(-78{ }^{\circ} \mathrm{C}\right)$ solution of propargyl bromide $(18.58 \mathrm{~g}, 0.125 \mathrm{~mol})$ in THF (50 $\mathrm{mL}$ ). The reaction mixture was stirred at $-78{ }^{\circ} \mathrm{C}$ for 3 hours, then at room temperature overnight. A brown solution was obtained. The solvents were removed in vacuo and the resulting viscous oil was hydrolysed with $50 \mathrm{~mL}$ of deionised water. The aqueous solution was washed three times with $150 \mathrm{~mL}$ of dichloromethane, the dichloromethane fractions were 
combined, and the organic layer was dried over $\mathrm{MgSO}_{4}$. The volatiles were removed and the crude product was purified by vacuum distillation $\left(70{ }^{\circ} \mathrm{C}, 5 \mathrm{mbar}\right)$. A $11.13 \mathrm{~g}$ portion of a yellow oil was obtained; yield $=82 \%$; same ${ }^{1} \mathrm{H}$ NMR data as in ref. $48 \mathrm{~d} ;{ }^{13} \mathrm{C}$ NMR $(50.3$ $\left.\mathrm{MHz}, \mathrm{CDCl}_{3}\right): \delta=36.3\left(\mathrm{C}_{4}\right), 75.1\left(\mathrm{C}_{6}\right), 77.1\left(\mathrm{C}_{5}\right), 119.1\left(\mathrm{C}_{2}\right), 129.6\left(\mathrm{C}_{1}\right), 136.9 \mathrm{ppm}\left(\mathrm{C}_{3}\right)$; IR $\left(\mathrm{CCl}_{4}\right): \quad \tilde{v}=3311(\mathrm{vs} ; \mathrm{Csp}-\mathrm{H}), 3117\left(\mathrm{w} ; \mathrm{Csp}^{2}-\mathrm{H}\right), 2923\left(\mathrm{w} ; \mathrm{Csp}^{3}-\mathrm{H}\right), 2134(\mathrm{w} ; \mathrm{C} \equiv \mathrm{C}), 1500$ $\mathrm{cm}^{-1}$ (vs; ring); FAB+ MS (NOBA): $m / z(\%): 213(14)\left[2 M+\mathrm{H}^{+}, 107(100)[M+\mathrm{H}]^{+}, 39\right.$ (24) $\left[\mathrm{CH}_{2} \mathrm{C} \equiv \mathrm{CH}\right]^{+}$.

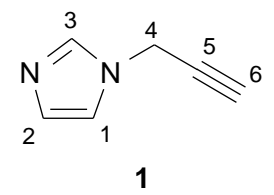

Synthesis of 1-(3-iodopropargyl)imidazole (2): A 4.07 g portion of $N$-iodosuccinimide $(18.1 \mathrm{mmol})$ and a $0.31 \mathrm{~g}$ portion of silver nitrate $(1.81 \mathrm{mmol})$ were added successively to a solution of $1(1.92 \mathrm{~g}, 18.1 \mathrm{mmol})$ in acetone $(100 \mathrm{~mL})$. The mixture was stirred at room temperature for 3 hours and then it was filtered. The solvent was removed on a rotary evaporator. The residue was washed with water $(50 \mathrm{~mL})$ and ether $(50 \mathrm{~mL})$. A $2.61 \mathrm{~g}$ portion of a beige solid was recovered; yield $=62 \%$. Elemental analysis of the solid showed large discrepancies between the experimental values and the calculated ones due to the presence of silver in the sample: elemental analysis calcd (\%) for $\mathrm{C}_{6} \mathrm{H}_{5} \mathrm{I}_{1} \mathrm{~N}_{2}$ (232.02): C 31.06, $\mathrm{H} \mathrm{2.17,} \mathrm{N}$ 12.07; found: C 26.56, H 1.86, N 10.08.

The solid was purified as follows: a 0.17 g portion of crude 2 was placed on a glass frit. The solid was washed with $25 \mathrm{~mL}$ of hot acetonitrile. The volume of the yellow filtrate was reduced on a rotary evaporator and the concentrated solution was placed in a freezer overnight. A crystalline powder precipitated out which was collected by suction filtration $(0.068$ g; yield $=40 \%)$. M.p. $227.7-232.4{ }^{\circ} \mathrm{C} ;{ }^{1} \mathrm{H}$ NMR $\left(200.1 \mathrm{MHz},\left[\mathrm{D}_{6}\right] \mathrm{DMSO}\right): \delta=5.05$ $\left(\mathrm{s}, 2 \mathrm{H} ; \mathrm{H}_{4}\right), 6.92\left(\mathrm{~s}, 1 \mathrm{H} ; \mathrm{H}_{1}\right), 7.21\left(\mathrm{~s}, 1 \mathrm{H} ; \mathrm{H}_{2}\right), 7.67 \mathrm{ppm}\left(\mathrm{s}, 1 \mathrm{H} ; \mathrm{H}_{3}\right) ;{ }^{13} \mathrm{C} \mathrm{NMR}(50.3 \mathrm{MHz}$, [D $]$ DMSO): $\delta=13.1\left(\mathrm{C}_{6}\right), 38.1\left(\mathrm{C}_{4}\right), 88.5\left(\mathrm{C}_{5}\right), 120.3\left(\mathrm{C}_{2}\right), 129.6\left(\mathrm{C}_{1}\right), 138.0 \mathrm{ppm}\left(\mathrm{C}_{3}\right)$; IR $(\mathrm{KBr}): \tilde{v}=3110\left(\mathrm{~s} ; \mathrm{Csp}^{2}-\mathrm{H}\right), 2921\left(\mathrm{w} ; \mathrm{Csp}^{3}-\mathrm{H}\right), 2174(\mathrm{~m} ; \mathrm{C} \equiv \mathrm{C}), 1503 \mathrm{~cm}^{-1}$ (vs; ring); ESI+ MS $\left(\mathrm{CH}_{3} \mathrm{CN}\right): m / z(\%): 232.95(100)[M+\mathrm{H}]^{+}$; elemental analysis calcd $(\%)$ for $\mathrm{C}_{6} \mathrm{H}_{5} \mathrm{I}_{1} \mathrm{~N}_{2}$ (232.02): C 31.06, H 2.17, N 12.07; found: C 32.69, H 2.44, N 14.06.

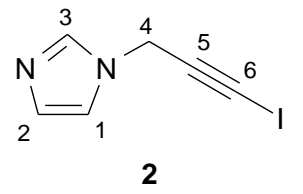


Synthesis of the co-crystal 1-(2,3,3-triiodoallyl)imidazole 1 morpholinium iodide (4): Under an inert atmosphere, a $25 \mathrm{~g}$ portion of morpholine $(0.287 \mathrm{~mol})$ was added dropwise to a cold $\left(0{ }^{\circ} \mathrm{C}\right)$ solution of iodine $(36.47 \mathrm{~g}, 0.143 \mathrm{~mol})$ in toluene $(200 \mathrm{~mL})$. The solution was stirred at room temperature for 2 hours. Alkyne 1 (5.08 g, $47.8 \mathrm{mmol}$ ) was added and the reaction mixture was stirred at room temperature overnight. Removal of the toluene in vacuo furnished a brown solid identified as 1-(2,3,3-triiodoallyl)imidazole.3 morpholinium iodide (3) by ${ }^{1} \mathrm{H}$ NMR spectroscopy; yield $=52.24 \mathrm{~g}(96 \%)$.

Solid 3 was placed on a glass frit, washed with acetonitrile, and the resulting yellow powder was dried in vacuo. The washed solid was identified as 1-(2,3,3-triiodoallyl)imidazole 1 morpholinium iodide (4) by ${ }^{1} \mathrm{H}$ NMR spectroscopy, elemental analysis, and single crystal Xray diffraction; yield $=26.81 \mathrm{~g}(80 \%)$. M.p. 132.7-133.9 ${ }^{\circ} \mathrm{C} ;{ }^{1} \mathrm{H}$ NMR $(200.1 \mathrm{MHz}$, [D $\left.\left.\mathrm{D}_{6}\right] \mathrm{DMSO}\right): \delta=3.11\left(\mathrm{t}, J=4.80 \mathrm{~Hz}, 4 \mathrm{H} ; \mathrm{H}_{8}\right), 3.76\left(\mathrm{t}, J=4.80 \mathrm{~Hz}, 4 \mathrm{H} ; \mathrm{H}_{7}\right), 4.96\left(\mathrm{~s}, 2 \mathrm{H} ; \mathrm{H}_{4}\right)$, 7.04 (s, 1H; $\left.\mathrm{H}_{1}\right), 7.16\left(\mathrm{~s}, 1 \mathrm{H} ; \mathrm{H}_{2}\right), 7.84\left(\mathrm{~s}, 1 \mathrm{H} ; \mathrm{H}_{3}\right), 8.69 \mathrm{ppm}$ (broad, 2H; $\left.\mathrm{H}_{9}\right) ;{ }^{13} \mathrm{C}$ NMR $(50.3$ $\left.\mathrm{MHz},\left[\mathrm{D}_{6}\right] \mathrm{DMSO}\right): \delta=38.1\left(\mathrm{C}_{6}\right), 43.8\left(\mathrm{C}_{8}\right), 62.0\left(\mathrm{C}_{4}\right), 64.2\left(\mathrm{C}_{7}\right), 114.8\left(\mathrm{C}_{5}\right), 119.9\left(\mathrm{C}_{2}\right)$, $129.6\left(\mathrm{C}_{1}\right), 138.4 \mathrm{ppm}\left(\mathrm{C}_{3}\right)$; ESI+ MS $\left(\mathrm{CH}_{3} \mathrm{CN}\right): \mathrm{m} / \mathrm{z}(\%): 972.54(58)\left[2 \mathrm{C}_{3} \mathrm{H}_{3} \mathrm{~N}_{2} \mathrm{CH}_{2} \mathrm{CI}=\mathrm{CI}_{2}\right.$ $+\mathrm{H}]^{+}, 701.77$ (31) $[M+\mathrm{H}]^{+}, 486.74$ (100) $\left[\mathrm{C}_{3} \mathrm{H}_{3} \mathrm{~N}_{2} \mathrm{CH}_{2} \mathrm{CI}=\mathrm{CI}_{2}+\mathrm{H}\right]^{+}, 232.97$ (55) $\left[\mathrm{C}_{3} \mathrm{H}_{3} \mathrm{~N}_{2} \mathrm{CH}_{2} \mathrm{C} \equiv \mathrm{CI}+\mathrm{H}\right]^{+}, 88.07$ (18) [morpholine $\left.+\mathrm{H}\right]^{+}$; elemental analysis calcd $(\%)$ for $\mathrm{C}_{10} \mathrm{H}_{15} \mathrm{I}_{4} \mathrm{~N}_{3} \mathrm{O}_{1}$ (700.87): C 17.14, H 2.16, O 2.28, N 6.00, I 72.43; found: C 17.74, H 2.15, O 3.36, N 6.57, I 71.88.
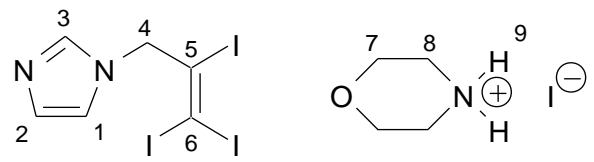

4

Synthesis of morpholinium iodide (6): Concentration to dryness of the filtrate coming from the washing of $\mathbf{3}$ with acetonitrile yielded a brown solid. Recrystallization of the solid from acetonitrile gave a crystalline powder identified as 6; yield $=15.2 \mathrm{~g}, 70.7 \mathrm{mmol}$. M.p. 195.2$203.0{ }^{\circ} \mathrm{C} ;{ }^{1} \mathrm{H}$ NMR $\left(200.1 \mathrm{MHz},\left[\mathrm{D}_{6}\right] \mathrm{DMSO}\right): \delta=3.12\left(\mathrm{~m}, 4 \mathrm{H} ; \mathrm{H}_{2}\right), 3.76\left(\mathrm{~m}, 4 \mathrm{H} ; \mathrm{H}_{1}\right), 8.69$ ppm (broad, $\left.2 \mathrm{H} ; \mathrm{H}_{3}\right) ;{ }^{13} \mathrm{C}$ NMR (50.3 MHz, [D $]$ DMSO): $\delta=43.8\left(\mathrm{C}_{2}\right), 64.1 \mathrm{ppm}\left(\mathrm{C}_{1}\right)$; ESI+ MS $\left(\mathrm{CH}_{3} \mathrm{CN}\right): m / z(\%): 518.05(6)[2 M+\text { morpholine }+\mathrm{H}]^{+}, 303.05(53)[M+$ morpholine + $\mathrm{H}]^{+}, 88.06$ (100) [morpholine $\left.+\mathrm{H}\right]^{+}$; elemental analysis calcd $(\%)$ for $\mathrm{C}_{4} \mathrm{H}_{10} \mathrm{I}_{1} \mathrm{~N}_{1} \mathrm{O}_{1}(215.03)$ : C 22.34, H 4.69, O 7.44, N 6.51; found: C 21.98, H 4.29, O 7.83, N 6.67.

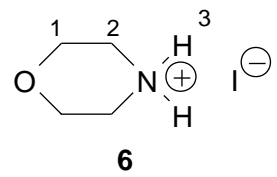


Synthesis of 1-(2,3,3-triiodoallyl)imidazole (5): A $5.99 \mathrm{~g}$ portion of 4 (12.3 mmol) was suspended in $100 \mathrm{~mL}$ of a saturated aqueous solution of $\mathrm{NaHCO}_{3}(\mathrm{pH}=8)$ and stirred for 3 hours. A 2.54 g portion of a yellow solid was obtained after suction filtration; yield $=89 \%$. M.p. 123.6-127.6 ${ }^{\circ} \mathrm{C} ;{ }^{1} \mathrm{H}$ NMR (200.1 MHz, [D $]$ DMSO): $\delta=4.95$ (s, 2H; H $), 6.98(\mathrm{~s}, 1 \mathrm{H}$; $\left.\mathrm{H}_{1}\right), 7.12\left(\mathrm{~s}, 1 \mathrm{H} ; \mathrm{H}_{2}\right), 7.73 \mathrm{ppm}\left(\mathrm{s}, 1 \mathrm{H} ; \mathrm{H}_{3}\right) ;{ }^{13} \mathrm{C} \mathrm{NMR}\left(50.3 \mathrm{MHz},\left[\mathrm{D}_{6}\right] \mathrm{DMSO}\right): \delta=36.6$ $\left(\mathrm{C}_{6}\right), 62.0\left(\mathrm{C}_{4}\right), 115.1\left(\mathrm{C}_{5}\right), 119.8\left(\mathrm{C}_{2}\right), 129.9\left(\mathrm{C}_{1}\right), 138.5 \mathrm{ppm}\left(\mathrm{C}_{3}\right)$; ESI+ MS $\left(\mathrm{CH}_{3} \mathrm{CN}\right): \mathrm{m} / \mathrm{z}$ (\%): $972.50(44)[2 M+\mathrm{H}]^{+}, 486.75(100)[M+\mathrm{H}]^{+}$; elemental analysis calcd $(\%)$ for $\mathrm{C}_{6} \mathrm{H}_{5} \mathrm{I}_{3} \mathrm{~N}_{2}$ (485.83): C 14.83, H 1.04, N 5.77; found: C 14.90, H 0.98, N 5.42.

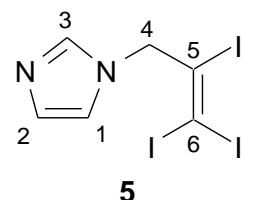

X-ray diffraction: Intensity measurements were carried out at the joint X-ray diffraction facility of the Institut Charles Gerhardt and the Institut Européen des Membranes, Université Montpellier II, France, at $173 \mathrm{~K}$, using an Oxford Diffraction Xcalibur-1 CCD diffractometer. The crystal-to-detector distance was $50 \mathrm{~mm}$; other data collection parameters were nearly identical in all four experiments. A total of 678 exposures were taken using $\omega$-scans with oscillations of $1^{\circ}$. The counting time per frame varied between 30 and $40 \mathrm{~s}$. The data were corrected for possible intensity decay and absorption using the empirical AbsPack procedure. ${ }^{[71]}$ All four structures were solved by direct methods using SIR2002 ${ }^{[72]}$ and refined by least-squares methods on $F$ using CRYSTALS. ${ }^{[73]}$ The structure of $\mathbf{6}$ was initially solved in the non-centrosymmetric space group $P 2_{1}$ as direct methods gave no solution in the centrosymmetric space group $P 2{ }_{1} / c$. Upon close inspection of the solution, an inversion center was added via the Addsym option of the PLATON program. ${ }^{[74]}$ For $\mathbf{2}, \mathbf{5}$, and $\mathbf{6}$, hydrogen positions were obtained from difference Fourier maps. In the case of $\mathbf{4}$, hydrogen atoms were positioned taking into account a possible hydrogen bonding interaction between the morpholine molecule and the imidazole moiety. The nitrogen and oxygen atoms of morpholine were assigned on the basis of observed bond distances $(\mathrm{d}(\mathrm{C}-\mathrm{O})=1.42 \AA$ and $\mathrm{d}(\mathrm{C}$ $\mathrm{N})=1.48 \AA$ ). As a consequence of assigning correctly these atoms, temperature factors became "normal". The nitrogen atom at the 3-position of the imidazole ring was assigned by postulating a hydrogen bond with morpholine. There is no interaction between the hydrogen at the 2-position of the imidazole ring and morpholine. Also, there is no interaction between this hydrogen and the iodide anion present in the lattice. Final $R$ values and relevant crystallographic data are given in Table 1. CCDC-623085 (2), CCDC-623086 (4), CCDC- 
623088 (5), and CCDC-623087 (6) contain the supplementary crystallographic data for this paper. These data can be obtained free of charge from the Cambridge Crystallographic Data Centre via www.ccdc.cam.ac.uk/data_request/cif. 


\section{Acknowledgment}

We thank Dr. Claude Gril from the Service Commun de Microscopie Electronique

(Université Montpellier II, Montpellier, France) for carrying out EDS measurements on compound 2. 


\section{References}

[1] a) J. A. Swift, V. A. Russell, M. D. Ward, Adv. Mater. 1997, 9, 1183-1186; b) V. A. Russell, C. C. Evans, W. Li, M. D. Ward, Science (Washington, D. C.) 1997, 276, 575-579; c) J. A. Swift, A. M. Pivovar, A. M. Reynolds, M. D. Ward, J. Am. Chem. Soc. 1998, 120, 5887-5894; d) J. A. Swift, A. M. Reynolds, M. D. Ward, Chem. Mater. 1998, 10, 4159-4168; e) C. C. Evans, L. Sukarto, M. D. Ward, J. Am. Chem. Soc. 1999, 121, 320-325; f) K. T. Holman, M. D. Ward, Angew. Chem. 2000, 112, 1719-1722; Angew. Chem. Int. Ed. 2000, 39, 1653-1656; g) J. A. Swift, M. D. Ward, Chem. Mater. 2000, 12, 1501-1504; h) K. T. Holman, A. M. Pivovar, J. A. Swift, M. D. Ward, Acc. Chem. Res. 2001, 34, 107-118; i) K. T. Holman, S. M. Martin, D. P. Parker, M. D. Ward, J. Am. Chem. Soc. 2001, 123, 4421-4431; j) A. M. Pivovar, K. T. Holman, M. D. Ward, Chem. Mater. 2001, 13, 3018-3031; k) K. T. Holman, A. M. Pivovar, M. D. Ward, Science (Washington, D. C.) 2001, 294, 1907-1911; 1) R. Custelcean, M. D. Ward, Cryst. Growth Des. 2005, 5, 2277-2287; m) M. D. Ward, Chem. Commun. 2005, 5838-5842.

[2] a) K. Biradha, D. Dennis, V. A. MacKinnon, C. V. K. Sharma, M. J. Zaworotko, J. Am. Chem. Soc. 1998, 120, 11894-11903; b) B. Moulton, M. J. Zaworotko, Chem. Rev. 2001, 101, 1629-1658.

[3] a) K. Endo, T. Sawaki, M. Koyanagi, K. Kobayashi, H. Masuda, Y. Aoyama, J. Am. Chem. Soc. 1995, 117, 8341-8352; b) P. Brunet, M. Simard, J. D. Wuest, J. Am. Chem. Soc. 1997, 119, 2737-2738.

[4] C. B. Aakeröy, J. Desper, B. Leonard, J. F. Urbina, Cryst. Growth Des. 2005, 5, 865873.

[5] a) G.-H. Cui, J.-R. Li, J.-L. Tian, X.-H. Bu, S. R. Batten, Cryst. Growth Des. 2005, 5, 1775-1780; b) L. Dobrzańska, G. O. Lloyd, H. G. Raubenheimer, L. J. Barbour, J. Am. Chem. Soc. 2005, 127, 13134-13135.

[6] a) J. S. Wilkes, Green Chem. 2002, 4, 73-80; b) P. Wasserscheid, T. Welton, Ionic Liquids in Synthesis, Wiley-VCH, Weinheim, 2003.

[7] a) J. D. Holbrey, K. R. Seddon, J. Chem. Soc., Dalton Trans. 1999, 2133-2139; b) A. E. Bradley, C. Hardacre, J. D. Holbrey, S. Johnston, S. E. J. McMath, M. Nieuwenhuyzen, Chem. Mater. 2002, 14, 629-635; c) M. Yoshio, T. Mukai, H. Ohno, T. Kato, J. Am. Chem. Soc. 2004, 126, 994-995. 
[8] a) J. D. Holbrey, K. R. Seddon, Clean Prod. Proc. 1999, 1, 223-236; b) T. Welton, Chem. Rev. 1999, 99, 2071-2083; c) P. Wasserscheid, W. Keim, Angew. Chem. 2000, 112, 3926-3945; Angew. Chem. Int. Ed. 2000, 39, 3772-3789; d) H. OlivierBourbigou, L. Magna, J. Mol. Catal. A: Chem. 2002, 182-183, 419-437; e) J. Dupont, R. F. de Souza, P. A. Z. Suarez, Chem. Rev. 2002, 102, 3667-3692; f) J. S. Wilkes, J. Mol. Catal. A: Chem. 2004, 214, 11-17.

[9] a) P. Bonhôte, A.-P. Dias, N. Papageorgiou, K. Kalyanasundaram, M. Grätzel, Inorg. Chem. 1996, 35, 1168-1178; b) H. Every, A. G. Bishop, M. Forsyth, D. R. MacFarlane, Electrochim. Acta 2000, 45, 1279-1284; c) K. Ito, N. Nishina, H. Ohno, Electrochim. Acta 2000, 45, 1295-1298; d) M. Yoshio, T. Mukai, K. Kanie, M. Yoshizawa, H. Ohno, T. Kato, Chem. Lett. 2002, 320-321.

[10] a) A. R. Chianese, B. M. Zeglis, R. H. Crabtree, Chem. Commun. 2004, 2176-2177; b) X.-J. Wan, F.-B. Xu, Q.-S. Li, H.-B. Song, Z.-Z. Zhang, Organometallics 2005, 24, 6066-6068.

[11] P. Metrangolo, H. Neukirch, T. Pilati, G. Resnati, Acc. Chem. Res. 2005, 38, 386-395.

[12] P. Metrangolo, G. Resnati, Chem. Eur. J. 2001, 7, 2511-2519.

[13] H. A. Bent, Chem. Rev. 1968, 68, 587-648.

[14] a) J. P. M. Lommerse, A. J. Stone, R. Taylor, F. H. Allen, J. Am. Chem. Soc. 1996, 118, 3108-3116; b) G. Valerio, G. Raos, S. V. Meille, P. Metrangolo, G. Resnati, J. Phys. Chem. A 2000, 104, 1617-1620; c) P. Romaniello, F. Lelj, J. Phys. Chem. A 2002, 106, 9114-9119; d) W. Wang, N.-B. Wong, W. Zheng, A. Tian, J. Phys. Chem. A 2004, 108, 1799-1805; e) J.-W. Zou, Y.-J. Jiang, M. Guo, G.-X. Hu, B. Zhang, H.C. Liu, Q.-S. Yu, Chem. Eur. J. 2005, 11, 740-751; f) S. J. Grabowski, E. Bilewicz, Chem. Phys. Lett. 2006, 427, 51-55.

[15] E. Corradi, S. V. Meille, M. T. Messina, P. Metrangolo, G. Resnati, Angew. Chem. 2000, 112, 1852-1856; Angew. Chem. Int. Ed. 2000, 39, 1782-1786.

[16] R. B. Walsh, C. W. Padgett, P. Metrangolo, G. Resnati, T. W. Hanks, W. T. Pennington, Cryst. Growth Des. 2001, 1, 165-175.

[17] N. Báthori, L. Bihátsi, P. Bombicz, M. Czugler, CrystEngComm 2003, 5, 42-44.

[18] R. Bianchi, A. Forni, T. Pilati, Chem. Eur. J. 2003, 9, 1631-1638.

[19] A. De Santis, A. Forni, R. Liantonio, P. Metrangolo, T. Pilati, G. Resnati, Chem. Eur. J. 2003, 9, 3974-3983.

[20] H. L. Nguyen, P. N. Horton, M. B. Hursthouse, A. C. Legon, D. W. Bruce, J. Am. Chem. Soc. 2004, 126, 16-17. 
[21] T. Caronna, R. Liantonio, T. A. Logothetis, P. Metrangolo, T. Pilati, G. Resnati, J. Am. Chem. Soc. 2004, 126, 4500-4501.

[22] J. Xu, X. Liu, T. Lin, J. Huang, C. He, Macromolecules 2005, 38, 3554-3557.

[23] A. C. B. Lucassen, M. Vartanian, G. Leitus, M. E. van der Boom, Cryst. Growth Des. 2005, 5, 1671-1673.

[24] J.-L. Syssa-Magalé, K. Boubekeur, P. Palvadeau, A. Meerschaut, B. Schöllhorn, CrystEngComm 2005, 7, 302-308.

[25] M. J. El Ghomari, R. Mokhlisse, C. Laurence, J.-Y. Le Questel, M. Berthelot, J. Phys. Org. Chem. 1997, 10, 669-674.

[26] S. Berski, Z. Ciunik, K. Drabent, Z. Latajka, J. Panek, J. Phys. Chem. B 2004, 108, 12327-12332.

[27] G. B. Ansell, J. Chem. Soc., Perkin Trans. 2 1973, 2036-2038.

[28] R. M. Claramunt, C. López, M. A. García, M. D. Otero, M. R. Torres, E. Pinilla, S. H. Alarcón, I. Alkorta, J. Elguero, New J. Chem. 2001, 25, 1061-1068.

[29] J. Grebe, G. Geiseler, K. Harms, K. Dehnicke, Z. Naturforsch., Teil B 1999, 54, 77-86.

[30] R. Bertani, E. Ghedini, M. Gleria, R. Liantonio, G. Marras, P. Metrangolo, F. Meyer, T. Pilati, G. Resnati, CrystEngComm 2005, 7, 511-513.

[31] O. Hassel, Science 1970, 170, 497-502.

[32] D. Phelps, A. Crihfield, J. Hartwell, T. W. Hanks, W. T. Pennington, R. D. Bailey, Mol. Cryst. Liq. Cryst. 2000, 354, 523-530.

[33] A. Crihfield, J. Hartwell, D. Phelps, R. B. Walsh, J. L. Harris, J. F. Payne, W. T. Pennington, T. W. Hanks, Cryst. Growth Des. 2003, 3, 313-320.

[34] M. Ghassemzadeh, K. Harms, K. Dehnicke, Chem. Ber. 1996, 129, 115-120.

[35] M. Ghassemzadeh, K. Harms, K. Dehnicke, Z. Naturforsch., Teil B 1997, 52, 772-774.

[36] R. Weiss, M. Rechinger, F. Hampel, A. Wolski, Angew. Chem. 1995, 107, 483-485; Angew. Chem. Int. Ed. Engl. 1995, 34, 441-443.

[37] M. Ghassemzadeh, K. Harms, K. Dehnicke, Chem. Ber. 1996, 129, 259-262.

[38] a) H. M. Yamamoto, J.-I. Yamaura, R. Kato, J. Mater. Chem. 1998, 8, 15-16; b) H. M. Yamamoto, J.-I. Yamaura, R. Kato, J. Am. Chem. Soc. 1998, 120, 5905-5913; c) H. M. Yamamoto, J.-I. Yamaura, R. Kato, Synth. Met. 1999, 102, 1448-1451.

[39] K. Gao, N. S. Goroff, J. Am. Chem. Soc. 2000, 122, 9320-9321.

[40] A. Sun, J. W. Lauher, N. S. Goroff, Science (Washington, D. C.) 2006, 312, 10301034. 
[41] N. S. Goroff, S. M. Curtis, J. A. Webb, F. W. Fowler, J. W. Lauher, Org. Lett. 2005, 7, 1891-1893.

[42] C. Laurence, M. Queignec-Cabanetos, T. Dziembowska, R. Queignec, B. Wojtkowiak, J. Am. Chem. Soc. 1981, 103, 2567-2573.

[43] C. Laurence, M. Queignec-Cabanetos, B. Wojtkowiak, J. Chem. Soc., Perkin Trans. 2 1982, 1605-1610.

[44] P. D. Rege, O. L. Malkina, N. S. Goroff, J. Am. Chem. Soc. 2002, 124, 370-371.

[45] J. A. Webb, J. E. Klijn, P. A. Hill, J. L. Bennett, N. S. Goroff, J. Org. Chem. 2004, 69, 660-664.

[46] R. Glaser, N. Chen, H. Wu, N. Knotts, M. Kaupp, J. Am. Chem. Soc. 2004, 126, 44124419.

[47] a) G. R. Desiraju, R. L. Harlow, J. Am. Chem. Soc. 1989, 111, 6757-6764; b) J. A. R. P. Sarma, F. H. Allen, V. J. Hoy, J. A. K. Howard, R. Thaimattam, K. Biradha, G. R. Desiraju, Chem. Commun. 1997, 101-102; c) A. D. Bond, J. Griffiths, J. M. Rawson, J. Hulliger, Chem. Commun. 2001, 2488-2489; d) G. Marras, P. Metrangolo, F. Meyer, T. Pilati, G. Resnati, A. Vij, New J. Chem. 2006, 30, 1397-1402.

[48] a) A. J. Hubert, H. Reimlinger, J. Chem. Soc. C 1968, 606-608; b) N. Goetz, A. Steimmig, B. Zeeh, H. Adolphi (BASF A.-G.), DE 2,750,030, 1979 [Chem. Abstr. 1979, 91, 103750c]; c) H. Ehrhardt, H. Mildenberger, Liebigs Ann. Chem. 1982, 5, 989-993; d) A. Casaschi, R. Grigg, J. M. Sansano, Tetrahedron 2001, 57, 607-615.

[49] R. M. Martín-Aranda, M. L. Rojas-Cervantes, A. J. López-Peinado, J. de D. LópezGonzález, Catal. Lett. 1994, 25, 385-392.

[50] a) H. Galons, I. Bergerat, C. Combet-Farnoux, M. Miocque, G. Decodts, G. Bram, J. Chem. Soc., Chem. Commun. 1985, 1730-1731; b) E. Díez-Barra, A. de la Hoz, A. Loupy, A. Sánchez-Migallón, Heterocycles 1994, 38, 1367-1374.

[51] a) M. Koyama, F. Kai, T. Tsuruoka, K. Miyauchi, K. Matsumoto, E. Akita, S. Inouye, T. Niida (Meiji Seika Kaisha, Ltd.), EP 80,051, 1983 [Chem. Abstr. 1983, 99, 194964e]; b) S. Inouye, T. Niida, K. Miyauchi, K. Matsumoto, E. Akita, M. Koyama, F. Kai, T. Tsuruoka (Meiji Seika Kaisha, Ltd.), US 4,563,472, 1986 [Chem. Abstr. 1986, 104, 207282e]; c) M. Koyama, N. Ohtani, F. Kai, I. Moriguchi, S. Inouye, J. Med. Chem. 1987, 30, 552-562.

[52] M. X.-W. Jiang, M. Rawat, W. D. Wulff, J. Am. Chem. Soc. 2004, 126, 5970-5971.

[53] R. H. Baughman, J. Org. Chem. 1964, 29, 964-965.

[54] B. Borgen, O. Hassel, C. Römming, Acta Chem. Scand. 1962, 16, 2469-2470. 
[55] C. J. Adams, L. E. Bowen, Dalton Trans. 2005, 2239-2240.

[56] H. Moon, R. Zeis, E.-J. Borkent, C. Besnard, A. J. Lovinger, T. Siegrist, C. Kloc, Z. Bao, J. Am. Chem. Soc. 2004, 126, 15322-15323.

[57] A. N. Sokolov, T. Friščić, L. R. MacGillivray, J. Am. Chem. Soc. 2006, 128, 28062807.

[58] C. Janiak, J. Chem. Soc., Dalton Trans. 2000, 3885-3896.

[59] J. F. Malone, C. M. Murray, M. H. Charlton, R. Docherty, A. J. Lavery, J. Chem. Soc., Faraday Trans. 1997, 93, 3429-3436.

[60] a) Y. Umezawa, S. Tsuboyama, K. Honda, J. Uzawa, M. Nishio, Bull. Chem. Soc. Jpn. 1998, 71, 1207-1213; b) P. Hobza, Z. Havlas, Chem. Rev. 2000, 100, 4253-4264.

[61] R. D. Bailey, L. L. Hook, R. P. Watson, T. W. Hanks, W. T. Pennington, Cryst. Eng. 2000, 3, 155-171.

[62] F. Bigoli, P. Deplano, M. L. Mercuri, M. A. Pellinghelli, E. F. Trogu, J. Chem. Res. (M) 1993, 0672-0682.

[63] M. Arca, F. Cristiani, F. A. Devillanova, A. Garau, F. Isaia, V. Lippolis, G. Verani, F. Demartin, Heteroatom Chem. 1997, 8, 139-146.

[64] M. Remelli, F. Pulidori, R. Guerrini, V. Bertolasi, J. Chem. Crystallogr. 1997, 27, 507-513.

[65] R. E. Melendez, C. V. Krishnamohan Sharma, M. J. Zaworotko, C. Bauer, R. D. Rogers, Angew. Chem. 1996, 108, 2357-2359; Angew. Chem. Int. Ed. Engl. 1996, 35, 2213-2215.

[66] a) Cambridge Structural Database, Version 5.26, November 2004 Release; b) F. H. Allen, Acta Crystallogr., Sect. B 2002, 58, 380-388.

[67] A. Parkin, I. D. H. Oswald, S. Parsons, Acta Crystallogr., Sect. B 2004, 60, 219-227.

[68] G. R. Desiraju, T. Steiner, The Weak Hydrogen Bond in Structural Chemistry and Biology; IUCr Monographs on Crystallography 9, Oxford University Press, Oxford, 1999, p. 54.

[69] T. A. Logothetis, F. Meyer, P. Metrangolo, T. Pilati, G. Resnati, New J. Chem. 2004, $28,760-763$.

[70] L. Brammer, G. Mínguez Espallargas, H. Adams, CrystEngComm 2003, 5, 343-345.

[71] CrysAlis ${ }^{\text {Pro }}$, Oxford Diffraction Ltd., 2006.

[72] M. C. Burla, M. Camalli, B. Carrozzini, G. L. Cascarano, C. Giacovazzo, G. Polidori, R. Spagna, J. Appl. Crystallogr. 2003, 36, 1103. 
[73] P. W. Betteridge, J. R. Carruthers, R. I. Cooper, K. Prout, D. J. Watkin, J. Appl. Crystallogr. 2003, 36, 1487.

[74] A. L. Spek, J. Appl. Crystallogr. 2003, 36, 7-13. 


\section{Legends}

Scheme 1. Syntheses of compounds 2-6.

Figure 1. View along $\vec{b}$ showing the layered structure of $\mathbf{2}$ and $\mathrm{N} \cdots$ I interactions between molecules in each layer.

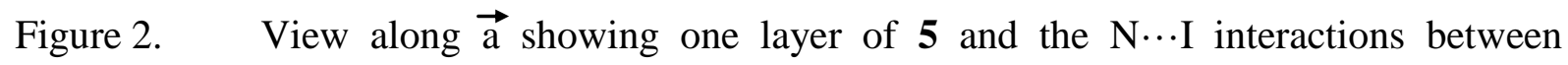
molecules in that layer.

Figure 3. View showing the organization of $\mathbf{4}$ in the crystalline state.

Figure 4. ORTEP diagram of 4 showing 50\% probability ellipsoids and the atom numbering scheme.

Figure 5. View showing the organization of 6 in the crystalline state. 
Table 1. Crystal Data and Experimental Details of Data Collection and Refinement for 2, 4, 5, and $\mathbf{6}$.

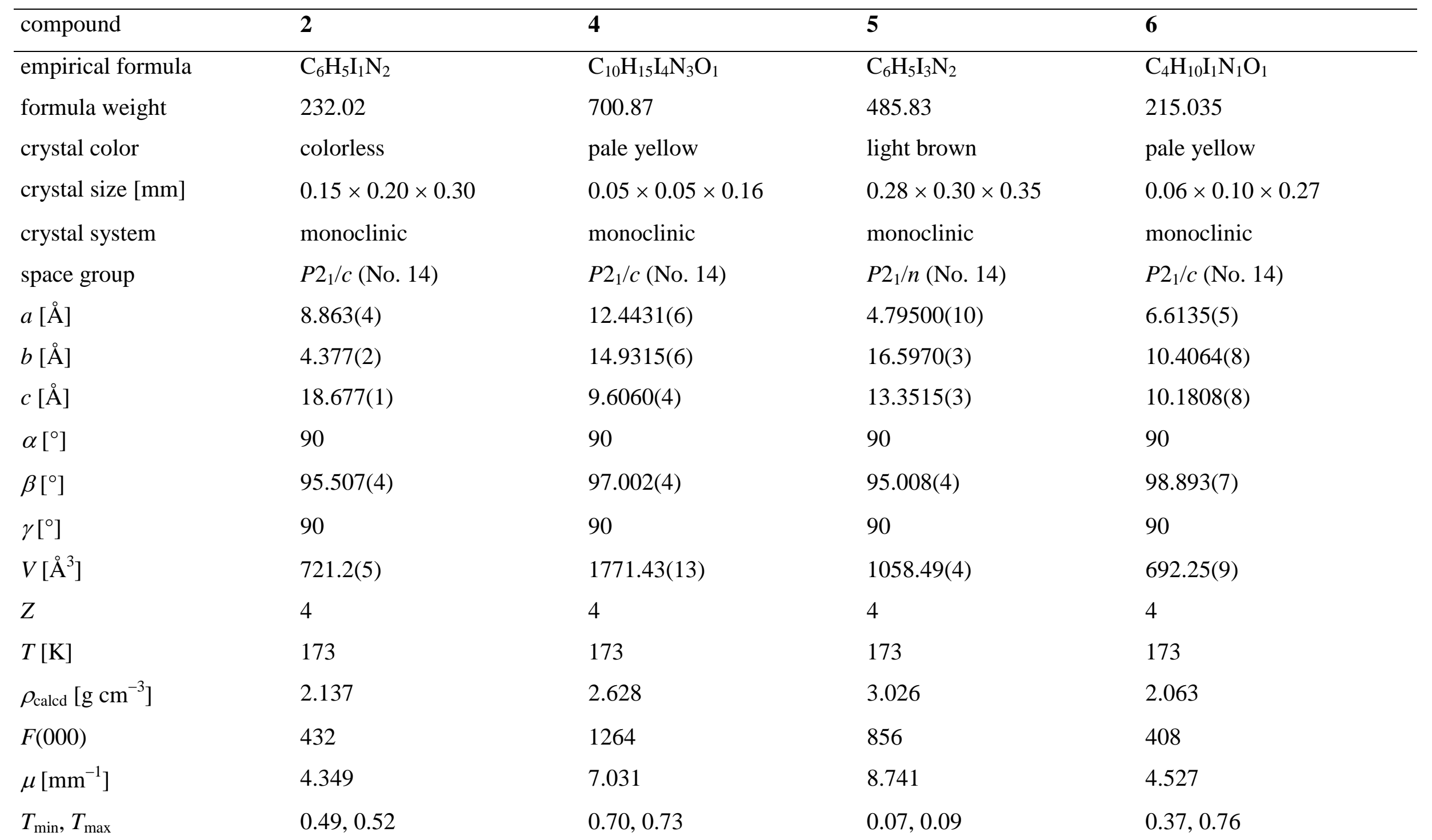




\begin{tabular}{|c|c|c|c|c|}
\hline Mo K $\alpha$ radiation $[\AA]$ & 0.71073 & 0.71073 & 0.71073 & 0.71073 \\
\hline$\theta$ range $\left[{ }^{\circ}\right]$ & $3.027-32.295$ & $3.163-32.304$ & $2.885-32.312$ & $3.118-32.258$ \\
\hline index ranges & $\begin{array}{l}-12 \leq h \leq 12,-6 \leq k \leq 6 \\
-27 \leq l \leq 27\end{array}$ & $\begin{array}{l}-18 \leq h \leq 17,-21 \leq k \leq 22 \\
-14 \leq l \leq 14\end{array}$ & $\begin{array}{l}-7 \leq h \leq 6,-24 \leq k \leq 24, \\
-19 \leq l \leq 19\end{array}$ & $\begin{array}{l}-9 \leq h \leq 9,-14 \leq k \leq 15, \\
-15 \leq l \leq 14\end{array}$ \\
\hline data collected & 12416 & 27703 & 20287 & 12928 \\
\hline unique data, $R_{\text {int }}$ & $2371,0.049$ & $5804,0.067$ & $3493,0.029$ & $4381,0.105$ \\
\hline observed data $\left(I_{\mathrm{o}}>2 \sigma\left(I_{\mathrm{o}}\right)\right)$ & 1518 & 2238 & 2710 & 1518 \\
\hline L.S. parameters, restraints & 82,0 & 163,0 & 100,0 & 65,0 \\
\hline$R,{ }^{[\mathrm{a}]} R_{\mathrm{w}}{ }^{[\mathrm{b}]}$ (obsd reflns) & $0.0501,0.0355$ & $0.0437,0.0404$ & $0.0208,0.0255$ & $0.0344,0.0201$ \\
\hline$R,{ }^{[\mathrm{a}]} R_{\mathrm{w}}{ }^{[\mathrm{b}]}$ (all reflns) & $0.0804,0.0361$ & $0.1354,0.0482$ & $0.0310,0.0257$ & $0.0603,0.0219$ \\
\hline weighting scheme, ${ }^{[\mathrm{c}]} A_{\mathrm{i}}$ & $13.7,0.705,9.65,6.66,1.05$ & $\begin{array}{l}8.30,-7.54,3.87,1.79 \\
-1.38\end{array}$ & $12.7,-6.97,10.7$ & $\begin{array}{l}-34.0,23.9,-69.7,22.6 \\
-29.9\end{array}$ \\
\hline max shift/esd & 0.000185 & 0.001276 & 0.001986 & 0.000920 \\
\hline goodness-of-fit & 1.1126 & 1.1424 & 0.9781 & 1.0155 \\
\hline$\Delta \rho_{\min }, \Delta \rho_{\max }\left[\mathrm{e} \AA^{-3}\right]$ & $-1.38,1.44$ & $-1.25,1.59$ & $-1.18,0.99$ & $-1.20,0.83$ \\
\hline
\end{tabular}

[a] $R=\Sigma\left\|F_{\mathrm{o}}|-| F_{\mathrm{c}}\right\| / \Sigma\left|F_{\mathrm{o}}\right| .[\mathrm{b}] R_{\mathrm{w}}=\left[\Sigma\left(\mathrm{w}\left(F_{\mathrm{o}}{ }^{2}-F_{\mathrm{c}}{ }^{2}\right)^{2}\right) / \Sigma\left(\mathrm{w}\left(F_{\mathrm{o}}{ }^{2}\right)^{2}\right)\right]^{1 / 2} .[\mathrm{c}] w=[$ weight $] *\left[1-(\Delta F / 6 \sigma(F))^{2}\right]^{2} ;[$ weight $]=1.0 /\left[A_{0} T_{0}(\mathrm{x})+\right.$ $\left.A_{1} T_{1}(\mathrm{x})+\ldots+A_{\mathrm{n}-1} T_{\mathrm{n}-1}(\mathrm{x})\right]$ where $A_{\mathrm{i}}$ are the Chebychev coefficients listed in the table and $\mathrm{x}=F_{\text {calc }} / F_{\max }$. 


\section{Text for the Table of Contents}

1-(3-Iodopropargyl)imidazole (2) and 1-(2,3,3-triiodoallyl)imidazole (5) self-assemble in the solid state to give polymeric chains. N...I halogen bonding interactions are responsible for the self-assembling process (see sketch, top). Despite their appreciable strength, these interactions are not sufficiently strong to compete with hydrogen bonding. In the X-ray crystal structure of the 1:1 co-crystal (4) between 5 and morpholinium iodide (6), the arrangement of the molecules is governed by $\mathrm{N}-\mathrm{H} \cdots \mathrm{O}$ interactions between nearby morpholinium cations and by $\mathrm{N}-\mathrm{H} \cdots \mathrm{N}$ hydrogen bonding between morpholinium cations and imidazolyl groups (bottom).

Graphic for the Table of Contents, here 


\section{Keywords}

donor-acceptor systems self-assembly crystal engineering $\cdot$ halogen bonding $\cdot$ hydrogen bonding 